\title{
Allium sativum L. (Garlic) Role in Osteoarthritis: A Systematic Review of Clinical Trials
}

\author{
Fateme Tavakoli-Far ${ }^{1 \mathbb{D}}$, Ehsan Amiri-Ardekani ${ }^{2,3,4, * \mathbb{E})}$, Ashkan Tehrany ${ }^{1 \mathbb{( D}}$ \\ 1 Faculty of Pharmacy, Ayatollah Amoli Branch, Islamic Azad University, Amol, Iran; f.tavakoli99@ yahoo.com (F.T.F.); \\ 2 Department of Phytopharmaceuticals (Traditional Pharmacy), Faculty of Pharmacy, Shiraz University of Medical \\ Sciences, Shiraz, Iran; ehsanamiri@sums.ac.ir (E.A.A.); \\ 3 Student Research Committee, Shiraz University of Medical Sciences, Shiraz, Iran \\ 4 Student Association of Indigenous Knowledge, Shiraz University of Medical Sciences, Shiraz, Iran \\ * Correspondence: ehsanamiri@sums.ac.ir;
}

Scopus Author ID 57217249366

Received: 5.12.2020; Revised: 28.12.2020; Accepted: 30.12.2020; Published: 2.01.2021

\begin{abstract}
Osteoarthritis is a chronic degenerative disease involving the joints and bones, causing their degradation over time. Inflammation, pain, and stiffness in joints are indicators of the disease. Pharmacotherapy cannot always be efficient and may cause side effects. So, adjuncts such as complementary herbs have become of note. Garlic is a herb well-known for its various therapeutic effects such as anti-bacterial, anti-hypertension, antioxidant and anti-inflammatory effects. Due to garlic's widespread use, studying its effects and mechanisms on inflammatory diseases such as osteoarthritis has been noteworthy. We searched Science Direct, Pubmed, Cochrane, and Google Scholar databases for all articles published until October 2020, based on PRISMA. Searched keywords were the following: [(garlic and arthritis), (garlic and osteoarthritis), (Garlic and OA), (Allium sativum and arthritis), (Allium sativum and osteoarthritis), (Allium sativum and OA)]. The results showed garlic, and its constituents have remarkable effects on improving OA symptoms through antioxidant and antiinflammatory pathways. Our review shows that groups receiving garlic as a treatment showed a significant reduction in pain and inflammatory factor levels and an improved physical function instead of the control group.
\end{abstract}

Keywords: garlic; osteoarthritis; Allium sativum; pain; stiffness;

(C) 2020 by the authors. This article is an open-access article distributed under the terms and conditions of the Creative Commons Attribution (CC BY) license (https://creativecommons.org/licenses/by/4.0/).

\section{Introduction}

Osteoarthritis (OA) is a chronic degenerative disease of the joints that can damage other tissues such as cartilage, bones, and muscles [1]. Depending on how OA is defined, estimations of prevalence and OA occurrences can differ from one another. The selected joints to be examined and the population under study also contribute to this matter too. It has recently been predicted that around 14 million Americans are afflicted with symptomatic knee OA (KOA), 3 million of whom are among racial and ethnic minorities. More than 50\% of KOA cases pertain to be patients over 65 years of age [2], and 303 million people were affected by OA worldwide in 2017. OA's high financial burden on the patient and the community is such that the OA Research Society International (OARSI) defined OA as a serious disease [3].

OA manifests as joint deformation and stiffness, general powerlessness, and reduced life quality $[1,4]$. Chronic pain in the joints and consequential disability is the main symptom and the basis of OA diagnosis. Contributing risk factors include genetics, trauma, aging, female gender, and obesity [5]. Pro-inflammatory adipocytokines such as Resistin can play a role in 
joint inflammation in OA [6, 7]. Inflammation and oxidative stress contribute to OA pain leading to joint homeostasis and degradation and lead to obesity-induced inflammation causing increased secretion of TNF- $\alpha$, which causes OA pathogenesis [8-10]. Also, obesity, due to its physical effects, is considered a risk factor for long-term activity limitations in patients with OA $[11,12]$. Increased levels of pro-inflammatory cytokines and free radicals, activation of cartilage-degrading enzymes, bone matrix remodeling, and increased chondrocytes apoptosis can also be possible pathogenicity mechanisms of OA [13]. There are numerous methods of treating OA, including pharmacotherapy.

Pharmacotherapy generally begins with acetaminophen, which is an analgesic medicine mostly used to reduce mild pain. Non-steroidal anti-inflammatory drugs (NSAIDs) such as naproxen, ibuprofen, and aspirin are relatively inexpensive drugs with anti-inflammatory and analgesic effects. They inhibit cyclooxygenase-2 (COX-2) enzymes and frequently also COX1 enzymes. Capsaicin and topical NSAIDs can be used for topical treatment of the OA when the symptoms are relatively mild. COX-2 inhibitors and ibuprofen are considered NSAIDs that show the least peptic ulcer side effects among COX-2 inhibitors, making them a safer choice. NSAIDs' adverse effects include peptic ulcers, cardiovascular complications, and a minor increase in blood pressure. Opioid analgesics can be administered orally, parenterally, or through a transdermal patch. OA's most powerful analgesic effects are usually obtained from transdermal opioid analgesics such as buprenorphine and fentanyl. Opioid analgesics are best reserved for patients with whom other analgesics can't achieve pain-relief or for patients with contraindications or who are unwilling to undergo surgery. Tramadol is probably the first choice in the OA treatment if the use of opioids is considered.

Also, anti-inflammatory effects have been discovered for glucocorticoids. They inhibit the production of collagenases mediating cartilage destruction in OA. Intra-articular glucocorticoids can be used particularly for patients for whom treatment with NSAIDs was ineffective in OA treatment. Another relatively high-priced supplement believed to be effective in relieving symptoms in the OA joint is hyaluronic acid. Hyaluronic acid has an important role in synovial fluid's viscoelastic features. It has been shown that it has a lower OA concentration than normal joints [14]. Corticosteroid injections maintain a short-term relief of flare-ups in the knee, whereas hyaluronic acid injections give a longer-lasting improvement. If the maximal medical treatment proves ineffective, total joint replacement is recommended [5].

Recommended adjunct treatments include exercise, which can reduce pain and disability, and supplements such as glucosamine and chondroitin, helping patients with moderate to severe knee OA [5].

Natural compounds used as complementary therapeutics in OA treatment have attracted attention; therefore, herbal remedies are a noteworthy choice for treatment. Garlic (Allium sativum L.) has been utilized throughout history as an herbal treatment for ailments ranging from the common cold to cardiovascular diseases, inflammations, non-inflammatory diseases, and tumors $[15,16]$. Compounds with medicinal value in OA treatment include but are not limited to alliinase, alliin, diallyl sulfide, ajoenes [17]. Some garlic compounds can modulate cytokine secretion and stimulate immune cells [18]; also, diallyl sulfide acts as an alleviator of inflammatory factors such as IL-1 $\beta$ induced cyclooxygenase 2 upregulation [19]. COX-2 overexpression in articular tissues is a typical occurrence in inflammatory joint diseases such as crystal-induced arthritis and OA. Various inflammatory stimuli, including interleukin-1 $\beta$ (IL-1 $\beta$ ), IL-17, and tumor necrosis factor (TNF), cause the induction of COX-2 in human joint tissues such as chondrocytes and synoviocytes. These cytokines seem to regulate COX-2 
expression in joint disease and the following production of prostaglandin E2 (PGE2) resulting in cartilage degradation, inflammation, and angiogenesis [20]. Garlic extracts can also function as an antioxidant. Also, analgesic effects have been achieved [16, 21].

Since current treatment methods are not entirely efficient in relieving pain and derangements, and commonly-prescribed medicines are also expensive and cause adverse effects in the long run, necessitating the investigation of newer therapeutics. So we will evaluate the clinical significance of 'garlic's role in the treatment of OA through a systematic review of clinical trials.

\section{Materials and Methods}

\subsection{Search strategy.}

We searched Science Direct, Pubmed, Cochrane, and Google Scholar databases for titles, abstracts, and keywords for all articles published up until October 2020, based on Preferred Reporting Items for Systematic Review and Meta-Analysis (PRISMA). The following keywords were searched: [(Garlic AND Arthritis), (Garlic AND Osteoarthritis), (Garlic AND OA), (Allium Sativum AND Arthritis ), (Allium Sativum AND Osteoarthritis), (Allium Sativum AND OA)]. Also, we only used articles published in English and Persian.

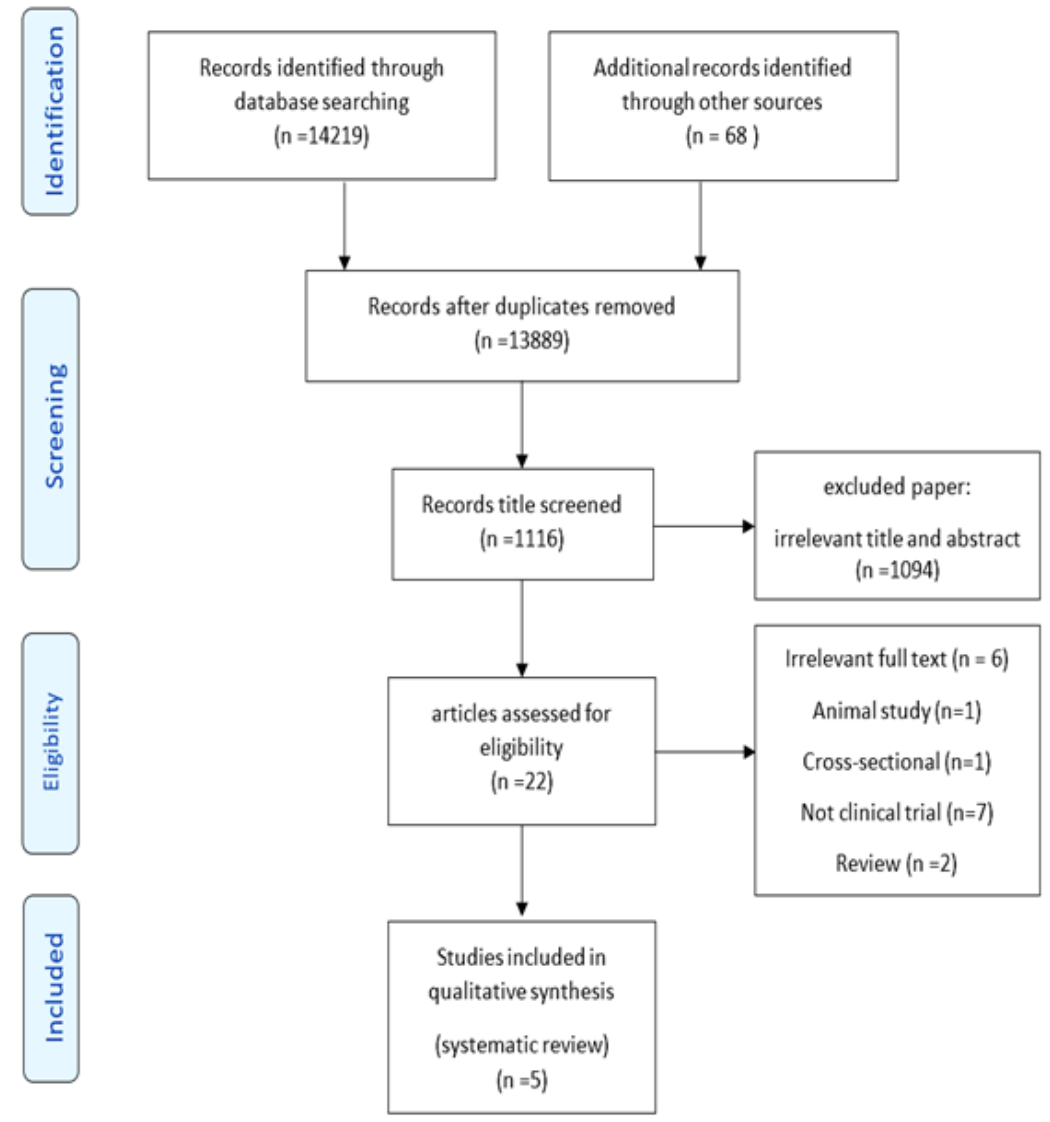

Figure 1. Flow chart of study selection.

\subsection{Study selection.}

We only included randomized articles that analyzed the effect of garlic on OA. In addition to articles obtained from searching databases, we reviewed cited articles and references to make sure about including related articles to our title. 


\begin{tabular}{|c|c|c|c|c|c|c|c|c|c|c|c|c|c|c|c|c|c|c|c|}
\hline Author & $\begin{array}{l}\mathbf{N} \text { Total } \\
\text { (case \& } \\
\text { control) }\end{array}$ & Gender & Age & Patient population & $\begin{array}{l}\text { Preparation, daily, } \\
\text { dose }\end{array}$ & $\begin{array}{l}\text { Study } \\
\text { duratio } \\
\text { n }\end{array}$ & $\begin{array}{l}\text { Total } \\
\text { WOM } \\
\text { AC }^{1,2}\end{array}$ & $\begin{array}{l}\text { WOMAC } \\
\text { Physical } \\
\text { function }\end{array}$ & $\begin{array}{l}\text { WOMA } \\
\text { C Joint } \\
\text { stiffness }\end{array}$ & $\begin{array}{c}\text { WOM } \\
\text { AC } \\
\text { Pain } \\
\text { severity }\end{array}$ & $\begin{array}{c}\text { VAS }^{3} \\
\text { Pain } \\
\text { severity }\end{array}$ & $\begin{array}{l}\text { TNF- } \\
\alpha\end{array}$ & BMI & $\begin{array}{l}\text { HA } \\
\mathbf{Q}^{4}\end{array}$ & IL-6 & $\begin{array}{l}\text { Collagen } \\
\text { ase }\end{array}$ & $\underset{13^{5}}{\text { MMP }}$ & $\begin{array}{c}\text { Side } \\
\text { effects }\end{array}$ & JADAD \\
\hline $\begin{array}{c}\text { Hosseinzadeh } \\
\text {-Attar et al. } \\
\text { [22] }\end{array}$ & $48(23,25)$ & $\begin{array}{c}48 \\
\text { Female }\end{array}$ & $50-57$ & $\begin{array}{c}\text { Obese }(\mathrm{BMI} \geq 30 \mathrm{Kg} / \mathrm{m} 2) \\
\text { women with mild to } \\
\text { moderate knee } \mathrm{OA}\end{array}$ & $\begin{array}{c}1000 \mathrm{mg} \text { garlic } \\
\text { supplement or } \\
\text { placebo }\end{array}$ & $\begin{array}{c}12 \\
\text { weeks }\end{array}$ & $\begin{array}{c}\text { P: } \\
0.006\end{array}$ & P: 0.004 & P: 0.073 & P: 0.621 & P: 0.073 & - & - & - & - & - & - & $\begin{array}{l}\text { Heartburn } \\
\text { in } 1 \text { case }\end{array}$ & 8 \\
\hline $\begin{array}{l}\text { Dehghani } e t \\
\text { al. }[23]\end{array}$ & $\begin{array}{c}76 \\
(39,37)\end{array}$ & $\begin{array}{c}76 \\
\text { Female }\end{array}$ & $50-75$ & $\begin{array}{c}\text { Post-menopausal } \\
\text { overweight or obese } \\
\text { women with with mild to } \\
\text { moderate knee } \mathrm{OA} \\
25 \leq \mathrm{BMI} \leq 40 \\
\mathrm{~kg} / \mathrm{m} 2)\end{array}$ & $\begin{array}{l}1000 \mathrm{mg} \text { garlic } \\
\text { twice-daily }\end{array}$ & $\begin{array}{c}12 \\
\text { weeks }\end{array}$ & - & - & - & & $\begin{array}{c}\mathrm{P}: \\
0.044\end{array}$ & $\begin{array}{c}\text { Not } \\
\text { signifi } \\
\text { cant }\end{array}$ & - & - & - & - & - & $\begin{array}{l}\text { Heartburn } \\
\text { in } 1 \text { case }\end{array}$ & 8 \\
\hline $\begin{array}{l}\text { Salimzadeh } e t \\
\quad a l .[24]\end{array}$ & $\begin{array}{c}76 \\
(39,37)\end{array}$ & $\begin{array}{c}76 \\
\text { Female }\end{array}$ & $50-75$ & $\begin{array}{c}\text { Postmenopausal } \\
\text { overweight or obese } \\
\text { women }(25 \leq \text { BMI } \leq 40 \\
\mathrm{kg} / \mathrm{m} 2) \text { with medically } \\
\text { diagnosed knee OA }\end{array}$ & $\begin{array}{l}1000 \mathrm{mg} \text { garlic } \\
\text { tablets } \\
500 \mathrm{mg} \text { tablets } \\
\text { twice a day }\end{array}$ & $\begin{array}{c}12 \\
\text { weeks }\end{array}$ & $\begin{array}{c}\text { P: } \\
0.295\end{array}$ & P: 0.163 & P: 0.174 & P: 0.287 & - & - & - & - & - & - & - & $\begin{array}{l}\text { No side } \\
\text { effect } \\
\text { reported }\end{array}$ & 8 \\
\hline $\begin{array}{l}\text { Hussein et al. } \\
2009[25]\end{array}$ & $\begin{array}{c}44 \\
(24,20) .\end{array}$ & $\begin{array}{l}\text { Not } \\
\text { mention } \\
\text { ed }\end{array}$ & $\begin{array}{l}\text { Not } \\
\text { menti } \\
\text { oned }\end{array}$ & Patients with KOA. & $\begin{array}{l}\text { Group I :garlic } \\
\text { capsules } 900 \mathrm{mg} \\
\text { daily } \\
\text { for } 8 \text { weeks. Group } \\
\text { II : glucosamine } \\
\text { sulfate } 1500 \mathrm{mg} \\
\text { daily for } 8 \text { weeks. }\end{array}$ & $\begin{array}{l}8 \text { weeks } \\
\text { for } \\
\text { Group I } \\
\& 12 \\
\text { weeks } \\
\text { for } \\
\text { Group } \\
\quad \text { II } \\
\end{array}$ & - & - & - & - & P: 0.037 & - & - & - & - & P: 0.001 & $\begin{array}{c}\mathrm{P:} \\
0.0001\end{array}$ & $\begin{array}{l}\text { No side } \\
\text { effect } \\
\text { reported }\end{array}$ & 3 \\
\hline $\begin{array}{l}\text { Hussein et al. } \\
2007[26]\end{array}$ & $\begin{array}{c}43 \\
(28,15)\end{array}$ & $\begin{array}{c}\text { Not } \\
\text { mention } \\
\text { ed }\end{array}$ & $\begin{array}{l}\text { Not } \\
\text { menti } \\
\text { oned }\end{array}$ & Patients with KOA & $\begin{array}{c}\text { group I } \\
\text { (comprehensive } \\
\text { rehabilitation) } \\
\text { and group II } \\
\text { (combined 900mg } \\
\text { garlic capsules } \\
\text { daily with } \\
\text { breakfast and } \\
\text { comprehensive } \\
\text { rehabilitation for } 8 \\
\text { weeks.) }\end{array}$ & 8 weeks & - & - & - & - & $\begin{array}{c}\mathrm{P}< \\
0.001\end{array}$ & $\begin{array}{c}\mathrm{P}< \\
0.001\end{array}$ & $\begin{array}{c}\mathrm{P}< \\
0.05\end{array}$ & $\begin{array}{c}\mathrm{P}< \\
0.001\end{array}$ & $\begin{array}{c}\mathrm{P}< \\
0.00 \\
1\end{array}$ & - & - & $\begin{array}{l}\text { No side } \\
\text { effect } \\
\text { reported }\end{array}$ & 2 \\
\hline
\end{tabular}

${ }^{1}$ All the evaluated factors reported as difference between the garlic and controlled group at the end of trial.

2 Western Ontario and McMaster Universities Osteoarthritis Index

${ }^{3}$ Visual analog scale

${ }^{4}$ Stanford Health Assessment Questionnaire

${ }^{5}$ Matrix metalloproteinase 13 
The searches were performed separately by EA and FT in the mentioned databases. FT extracted and reviewed the data, and FT, AT, and EA wrote the manuscript. Disagreements were resolved by team discussion. We searched based on PRISMA to select relevant articles, and 15 articles were involved in our studies, 10 of which were excluded due to being animal studies, cross-sectional study, reviews, irrelevant full-text articles, and having a modified JADAD score below 2 (figure 1). The quality of the articles was measured based on the modified JADAD (Table S1). Extracted information includes the number of participants, age, preparation, daily dose, species, treatment duration, and statistical analysis that is shown in Table 1.

\subsection{Publication Ethics}

The authors declare that the investigations were carried out following the rules of the Declaration of Helsinki of 1975.

\section{Results}

We used [(garlic and arthritis), (garlic and osteoarthritis), (garlic and OA), (Allium Sativum and arthritis), (Allium sativum and osteoarthritis), (Allium Sativum and OA)] as keywords to find randomized clinical trials in which garlic and/or its components were used as an intervention to improve the therapeutic indices of OA. Out of 14,219 articles from the search, we screened 1,116 by their titles. We found 22 articles that were clinical trials and investigated the effects of garlic in treating or reducing OA symptoms. Seventeen of the remaining 22 articles were excluded because of the aforementioned reasons (Figure 1). Finally, five clinical trial articles were reviewed. Three of the five reviewed articles were journal articles, and two of them were poster papers.

All studies were clinical trials. The shortest duration of treatment with garlic was 8 weeks. The most common and the longest duration of treatment was 12 weeks. The frequent dose of garlic was $1000 \mathrm{mg}$. Also, two studies used $900 \mathrm{mg}$ of garlic as an intervention. None of them reported any side effects except two cases of heartburn in two studies. Clinical trials were performed on 287 women with OA, the youngest of whom was 50 years old, and the oldest of whom was 75 years old. Four studies measured pain severity based on a visual analog scale (VAS). One study reported the outcome pain severity based on Western Ontario and McMaster Universities Osteoarthritis Index (WOMAC) and VAS. Another study reported pain severity based on WOMAC. Three studies analyzed the joint symptoms and used WOMAC to do so. One study measured fasting serum concentrations of resistin and tumor necrosis factoralpha (TNF- $\alpha$ ). Another one evaluated serum metalloproteinase 13 and collagenase levels. Another study measured the synovial fluid level of interleukin $1 \beta$ (IL-1 $\beta$ ), interleukin 6 (IL-6), and TNF- $\alpha$.

\section{Discussion}

Since ancient times, humans have used garlic for its cardioprotective, anti-tumor, antidiabetic, anti-inflammatory, and anti-microbial properties. These properties are due to the presence of various bioactive substances such as allicin (accountable for the majority of the possible pharmacological functions [27]) and other organosulfur, selenium, and arginine as micronutrients, and phenolic and steroid compounds in garlic. Each of the garlic compounds 
can show its biological properties and, therefore, can be used as a treatment or adjunctive therapy in the treatment of some diseases[28]. Because of the reported positive effects of garlic supplementation on improving OA symptoms, the parameters contributing to OA, on which the effects of garlic have been studied, are discussed in the following section.

\subsection{Age and population.}

Three of the articles studied only postmenopausal women of 55 years and above (mean: 59.6, 58.9, and 58.9), which can show good accuracy in the effectiveness of garlic in improving the symptoms of OA despite the other two articles didn't mention the age and population in their study. We surmise that these articles studied this specific population because the incidence of OA is more common in women than men [29]. Also, OA has an $80 \%$ prevalence in women between 46 and 65 [30]. Among women, postmenopausal ones are more likely to develop OA. This may be due to a decrease in estrogen, thus increasing the secretion of pro-inflammatory factors like IL-6, IL-1, and TNF- $\alpha$ [31].

\subsection{BMI \& obesity.}

One of the risk factors involved in this disease is obesity. Research has shown that the risk of KOA increases by 35\%, with every $5 \mathrm{~kg} / \mathrm{m} 2$ increase in BMI [32]. Decreased BMI following weight loss in women was also associated with a reduced OA risk [33]. On the other hand, obesity is directly related to increased adipocytokines concentrations such as resistin, leptin, visfatin, vaspin, and omentin, which all are suggested to have a role in OA pathogenesis and development [34]. Adipocytokines are produced by immune cells and adipocytes [22]. Obesity can increase OA's chances in people, especially the elderly, both through physical pressure on the joints in different parts of the body and through biochemical pathways [35].

Dehghani et al. didn't observe any significant difference between the garlic and placebo groups in the BMI and fat percentage in a 12-week study with twice-daily use of $500 \mathrm{mg}$ garlic tablets equivalent to 1250 micrograms of allicin [23]. Also, Hosseinzadeh et al. reported that the daily use of $1000 \mathrm{mg}$ garlic tablets containing $2.5 \mathrm{mg}$ of allicin for 12 weeks could show no evidence of significant changes between the two groups in BMI and weight [22]. Likewise, in the Salimzadeh et al. study, after 12 weeks of using $500 \mathrm{mg}$ garlic tablets twice a day equivalent to $2.5 \mathrm{mg}$ allicin, no considerable differences between the two groups were reported in weight loss BMI reduction [24]. Hussein et al., 2007 administrated $900 \mathrm{mg} / \mathrm{day}$ of garlic capsules for 8 weeks with breakfast beside exercises that increase the foot's strength and flexibility and electrotherapy for 3 times a week until the end of the clinical trial. This intervention was also able to reduce the BMI significantly only in the garlic group [26]. Hussein et al., 2009 didn't mention any change in BMI between the control and garlic group [25]. Although Hosseinzadeh et al., and Salimzadeh et al., could not show a significant difference between the two groups, they reported a significant decrease in fat percentage and BMI at the end of the trial in the garlic group. On the other hand, Dehghani et al. reported a higher fat intake in the garlic group compared to the placebo group (P: 0.036) at the end of the trial. It may have affected the final result. The data on garlic efficacy in weight loss, decreasing fat percentage, and BMI reduction are not compatible. Based on recent studies, garlic only affects waist circumference. It does not affect weight loss and BMI [36]. In contrast, a clinical study has shown that garlic can cause weight loss in women with metabolic syndrome [37].The mechanisms proposed for weight loss by garlic are a reduction in blood triglyceride levels, 
tissue adiposity, and a reduction in cholesterol and free fatty acids[38]. In addition to the previous mechanisms, garlic can also exhibit anti-obesity properties by activating the AMPactivated protein kinase (AMPK) mechanism. This mechanism increases thermogenesis and reduces the expression of genes that have a key role in adipogenesis[39]. 1,2-vinyldithiin, one of the organosulfurs of garlic, can reduce the expression of C / EBP $\alpha$ PPARg2, and LPL (lipoprotein lipase) in addition to PPARg activity in human adipocytes [40].

These observations determined that garlic may decrease fat percentage and BMI, and this effect may be dose-dependent. However, changing the intervention duration may yield more reliable data, too. Studies conducted on this hypothesis are limited; more research with longer durations of intervention or different therapeutic doses of garlic supplements may yield different results. If garlic supplementation causes a decrease in weight and BMI it can help in OA through decreasing physical tension on the knee.

\subsection{Immune system role in osteoarthritis progression.}

Both innate and adaptive immunity roles in OA progression are well-known. Factors contributing to inflammation signaling include cytokines such as interleukins, tumor necrosis factor $\alpha$, surface-expressed pattern recognition receptors, and damage-associated molecular patterns that motivate the enzymatic processes and cause the degradation of cartilage matrix in OA [41].

\subsubsection{Pro-inflammatory cytokines.}

Pro-inflammatory factors play a role in this disease's pathogenesis, like causing pain or destruction of cartilage [9, 24]. Chondrocytes produce pro-inflammatory cytokines such as IL$1 \beta$, IL-6, and TNF $\alpha$, whose levels are elevated in end-stage OA[42-44]. The increasing of proinflammatory cytokines secretion may be due to an imbalance of biochemical pathways in the production of reactive oxygen species (ROS), leading to the destruction of normal cell molecules such as proteins or DNA ultimately cell dysfunction. The elevation of ROS concentration is called oxidative stress[45]. Also, garlic extracts have an antioxidant effect due to the presence of allicin, thiosulfinates, S-allylcysteine (SAC), phenolic compounds, ajoenes [46], S-allyl-mercapto cysteine (SAMC) [47], and garlic polysaccharide and its derivatives [48]. To reveal the possible positive effect of garlic on this pathway, we suggest administrating purified molecules and polysaccharides of garlic as an intervention in future studies.

\subsubsection{TNF- $\alpha$.}

TNF- $\alpha$ is a known key inflammatory factor whose expression is enhanced by another inflammatory factor called resistin, produced in fibroblasts in synovial fluids in OA[45]. Induction of pain in OA patients is due to increased TNF- $\alpha$ in synovial fluids and activation of sensory neurons by TNF- $\alpha$. TNF- $\alpha$ can also cause pain by stimulating the production of other pro-inflammatory factors [23].TNF- $\alpha$ degenerates fibroblasts and chondrocytes by causing inflammation in the synovial fluid, destroying cartilage [49].

Two reviewed studies investigated the effect of garlic on TNF- $\alpha$ concentration before and after the trial. A significant change in TNF- $\alpha(\mathrm{P}<0.001)$ was seen in the Hussein et al., 2007 study with daily consumption of $900 \mathrm{mg}$ of garlic capsules for 8 weeks with breakfast. In the Dehghani et al. study, even though the trial duration (12 weeks) and the daily dose (1000 mg) were longer and more than the Hussein et al. 2007 study, no significant changes in TNF- 
$\alpha$ were reported after the trial. Since the difference in dose was not very great, this contradiction may be either due to the unequal periods of administration or the fact that the data might not be sufficient and require further research, since there were only two researches done on this case. The data cannot be fully trusted, as TNF- $\alpha$-reducing effects using garlic were observed in in-vitro studies. For example, garlic-derived compounds can prevent the transcription of several cytokine genes that contribute to pro-inflammatory responses, such as TNF- $\alpha$, IL$1 \beta$, and IL-6[50-53]. A meta-analysis of randomized controlled trials has also reported a significant reduction in the TNF- $\alpha$ serum concentration due to supplementation with garlic extract[54, 55].

On the other hand, one of the main aqueous portions of garlic extract is $\mathrm{S}$-allyl-mercapto cysteine (SAMC). Investigations have shown that SAMC could down-regulate the IL-1 $\beta$, IL6 , and TNF- $\alpha$ elevated in OA remarkably[47]. Three other trials didn't measure the TNF- $\alpha$ concentration. So it appears that garlic can decrease TNF- $\alpha$ concentration in different health problems such as OA.

\subsubsection{Resistin.}

Resistin is an adipokine hormone that is produced by adipose tissue [56]. In patients with a knee injury, the resistin levels in and serum and synovial fluid are increased [57]. Resistin is responsible for cartilage damage and synovial inflammation [58]. Also, it changes chondrocyte metabolism and elevates the expression of MMP-1 and MMP-13 [59]. Resistin also upregulates IL-6, IL-1 $\beta$, and TNF- $\alpha$ production in the cartilage[57]. In a cross-sectional analysis, circulating resistin was increased in OA patients [60]. One study reported that the Resistin level in circulation is elevated in people with diabetes and obese people [61].

In reviewed articles, only Dehghani et al. measured the resistin serum concentration and reported a remarkable decrease in the garlic group (P: 0.008) due to garlic supplementation and no significant difference between them (P: 0.558). Since the resistin is correlated positively with local pro-inflammatory factors and cartilage degradation at the site of inflammation [62], and some component of garlic such as 1,2-vinyldithiin could decrease the preadipocytes differentiation, made in subcutaneous adipose tissue, through the reduction in gene expression of two critical families of transcription factors, C/EBP and PPAR [40], we guess that topical formulation of garlic may be more efficient in diminishing the resistin concentration. This prospect should be evaluated more in future studies.

\subsubsection{3. $I L-6$}

IL-6 is another pro-inflammatory cytokine that is upregulated commonly in OA [63]. IL-6 has pleiotropic effects on the bone, cartilage, and immune system [64].

Only one reviewed article, Hussein et al., 2007, evaluated the IL-6 concentration and reported a significant decrease in IL-6 level in the garlic group after administering $900 \mathrm{mg} /$ day garlic capsule with breakfast for 8 weeks $(\mathrm{p}<0.001)$. Since we only have data from one report on this case, we cannot judge the accuracy of this result. We suggest that further research be done on the IL-6 level in OA patients in future studies. But other studies on IL- 6 concentrations after consuming garlic show conflicting results. The efficacy of garlic in the reduction of IL-6 level is not determined. Some researchers didn't report the effective decrease in IL-6 level ( $p$ $>0.05$ )[54] though another meta-analysis of the randomized controlled trial reported a remarkable reduction in IL-6 level $(\mathrm{P}<0.001)$ [55]. 
As we said, IL-6 can be down-regulated by garlic extracts, especially by allicin and SAMC [47]. Studies have also shown that cell incubation with alliin stopped the increase in the expression of the IL- 6 gene and the protein levels of IL-6 [65]. So IL-6 decrease can be proposed as one of the garlic mechanisms in OA treatment.

\subsubsection{4. $I L-1 \beta$.}

IL- $1 \beta$ is another pro-inflammatory cytokine, accepted as the most important cytokine in the OA process [66]. IL-1 $\beta$ is produced in chondrocytes and expedites cartilage degeneration in OA [67]. IL-1 $\beta$ levels, much like IL-6 and other inflammatory cytokines, are decreased by garlic composites. There is no study on IL-1 $\beta$ level in OA patients. On the other hand, due to garlic's potential in reducing IL- $1 \beta$ level, and the important role of IL-1 $\beta$ in OA progression, we suggest further researches on this issue.

\subsubsection{Matrix metalloproteinases (MMPs).}

The Matrix metalloproteinases (MMPs) family, the $\mathrm{Zn}^{2+}$ metalloproteinases, are defined as a key factor in joint destruction. Also, there is a class of MMPs called Collagenases [68] .Cytokines and growth factors induce MMP synthesis in chondrocytes and synovial cells[69]. MMP-2, MMP-9, MMP-13, MMP14, and MMP-16 play role in bone and skeletal pathologies [47]. They cleave the type II collagen and aggrecan and cause the degradation of extracellular matrix components[70]. Collagen type II is degenerated by MMP-1 and MMP-13 in articular cartilage[71]. The biological activities of MMPs are majorly under the control of the tissue inhibitor of matrix metalloproteinase-1 (TIMP-1). Unbalance between MMPs and TIMPs causes OA progress. An increase in levels of MMP-2, MMP-9, and MMP-13 was observed, whereas the TIMP-1 level was decreased due to down-regulation in murine OA cartilages. SAMC can counter these effects [72].

MMPs were measured only in one study. Hussein et al., 2009, at the end of an 8-week supplementation with $900 \mathrm{mg} /$ day garlic capsule, reported an effective decrease in MMP-13 level (P: 0.0001). They also revealed a significant reduction in collagenase (P: 0.001) in the same clinical trial. SAMC, in addition to other components of garlic extract, can significantly cause this effect because investigations have shown that SAMC could elevate the TIMP-1 level and reduce MMPs [47]. Further research may show the role of garlic in MMPs decrease that worth evaluating and may be a mechanism of garlic in OA treatment.

\subsubsection{WOMAC.}

\subsubsection{Total WOMAC.}

The Western Ontario and McMaster Universities Osteoarthritis Index (WOMAC) is a self-administered health evaluation tool for patients with OA of hip or knee [73]. Three main subscales of WOMAC consist of pain, physical function, and stiffness, which includes 24 items in total [74].

Salimzadeh et al. reported no significant change in total WOMAC score (P: 0.295) after 12 weeks using $500 \mathrm{mg}$ garlic tablets twice a day, whereas Hosseinzadeh-Attar et al. reported P: 0.006 after daily use of $1000 \mathrm{mg}$ garlic tablets containing $2.5 \mathrm{mg}$ of allicin for 12 weeks. It seems that less frequent garlic supplementation is more efficient in decreasing the WOMAC 
score. Other reviewed articles didn't report any data on total WOMAC, and current data is not efficient to determine the real effect of garlic on total WOMAC score.

\subsubsection{Pain.}

Pain is one of the most obvious symptoms of OA. Pain may be of mechanical such as joint damage [75] or neurological origin [76]. It may also be caused by inflammatory factors [24]. Pain in the early stages of the disease has a mechanical origin that gets worse with activity and gets better with rest [76]. Chronic peripheral pain has evidence of central sensory stimulation in almost all patients. Stimulation and activation of sensory neurons can also be mediated by inflammatory factors such as TNF- $\alpha$. Comorbidities like depression [77] and patient-related factors such as sex, stress, adverse life experiences, and gut microbiome stimulate the development of central sensitization and present to the pain phenotype $[75,78,79]$. Pain has 5 questions in WOMAC.

The pain was measured by WOMAC and VAS. Three studies reported a remarkable decrease in joint pain severity based on VAS between the two groups. Salimzadeh et al. didn't report a considerable difference between the placebo and intervention groups' pain severity based on WOMAC. However, a significant change in the garlic group was reported at the end. Also, Hosseinzadeh-Attar et al. measured pain severity based on both VAS and WOMAC and observe no significant decrease in pain severity. However, interestingly, a considerable change in the garlic group was reported at the end of the trial. We should mention that despite VAS is highly responsive, validated, and comparable to WOMAC [23], the WOMAC and VAS results of the Hosseinzadeh-Attar et al. study were incompatible with each other. We suggest this reduction in pain severity is due to the effect of reducing the levels of inflammatory factors rather than the effectiveness of garlic in mechanical mechanisms. The probable topical formulation of garlic may be more effective in local pain because of local secretion of proinflammatory factors, and this view should be examined in future clinical studies.

\subsubsection{Physical function.}

Physical function is another WOMAC subscale that has 17 questions. OA due to cartilage degeneration, pain, stiffness, and decreased muscle strength cause limitation in movements in weight-bearing joints like knee and/or hip and disable the joints [80, 81]. Daily activities such as getting in and out of a bath, walking, and simple housework are prohibited as the disease progresses and becomes more severe [82]. Studies have also reported that knee pain is a key factor of physical disability in KOA [83-87].

Only one of the two studies which measured physical function by WOMAC scale reported significant improvement by $1000 \mathrm{mg} /$ daily garlic supplement within 12 weeks between the two groups (P: 0.004 ) [22]. Although Salimzadeh et al., the study did not report a significant change in the reduction of physical function between the two groups, it showed a noteworthy change in the garlic's physical function at the end of the trial[24]. As both Hosseinzadeh-Attar et al., and Salimzadeh et al., studies reported a remarkable decrease in pain in garlic group, it seems that improvement in physical function is following the improvement in pain severity which we guess the mechanisms involved in pain improvement due to garlic supplementation is following to the decrease in TNF- $\alpha$ concentration.

\subsubsection{Joint stiffness.}


Stiffness can be determined as a restricted range of motion impacting a patient's capacity to do daily life activities [88]. It also is a subscale of WOMAC and has 2 questions. None of the two studies which evaluated Joint stiffness reported a considerable improvement in joint stiffness between the two groups at the end of the trial (P: 0.174[24] and P: 0.073[22]). Interestingly, both of them reported a significant change in the garlic group (P: 0.013[24] and P: 0.12[22]). The efficacy of garlic in improving joint stiffness should be more investigate with the longer duration of supplementation and various doses.

\section{Conclusions}

This systematic review showed that garlic and its extract might be a novel treatment for OA to improve disease symptoms. Based on current evidence, we recommend duration and dosage of treatment with garlic is at least $1000 \mathrm{mg}$ for 12 weeks. Below these values, it is unlikely that the healing effects of garlic can be seen. However, current randomized clinical trials have limitations, including the missing information, did not complete the study due to NSAIDs' heartburn and use due to severe knee pain or because of incomplete laboratory tests. More double-blind, large sample size randomized clinical trials on 'garlic's role on OA that evaluates BMI, pro-inflammatory cytokines, pain, stiffness, and physical function with various duration and doses are required in the future to prove or modify our results. We also recommend that researchers evaluate different chemical compounds of this valuable medicinal plant for OA treatment that may cause a decrease in needed dose and better treatments.

\section{Funding}

This research received no external funding.

\section{Acknowledgments}

This research has no acknowledgment.

\section{Conflicts of Interest}

The authors declare no conflict of interest.

\section{References}

1. Arden, N.; Nevitt, M.C. Osteoarthritis: epidemiology. Best practice \& research Clinical rheumatology 2006, 20, 3-25, https://doi.org/10.1016/j.berh.2005.09.007.

2. Vina, E.R.; Kwoh, C.K. Epidemiology of osteoarthritis: literature update. Current opinion in rheumatology 2018, 30, https://doi.org/10.1097/BOR.0000000000000479.

3. Kloppenburg, M.; Berenbaum, F. Osteoarthritis year in review 2019: epidemiology and therapy. Osteoarthritis and Cartilage 2020, 28, 242-248, https://doi.org/10.1016/j.joca.2020.01.002.

4. Buckwalter, J.A.; Saltzman, C.; Brown, T. The impact of osteoarthritis: implications for research. Clinical $\begin{array}{llll}\text { Orthopaedics and Related 2004, } & \text { S27, }\end{array}$ https://doi.org/10.1097/01.blo.0000143938.30681.9d.

5. Sinusas, K. Osteoarthritis: diagnosis and treatment. American family physician 2012, 85, 49-56.

6. Savage, D.B.; Sewter, C.P.; Klenk, E.S.; Segal, D.G.; Vidal-Puig, A.; Considine, R.V.; O’Rahilly, S. Resistin/Fizz3 expression in relation to obesity and peroxisome proliferator-activated receptor- $\gamma$ action in humans. Diabetes 2001, 50, 2199-2202, https://doi.org/10.2337/diabetes.50.10.2199.

7. Presle, N.; Pottie, P.; Dumond, H.; Guillaume, C.; Lapicque, F.; Pallu, S.; Mainard, D.; Netter, P.; Terlain, B. Differential distribution of adipokines between serum and synovial fluid in patients with osteoarthritis. Contribution of joint tissues to their articular production. Osteoarthritis and Cartilage 2006, 14, 690-695, https://doi.org/10.1016/j.joca.2006.01.009. 
8. Fernandes, J.C.; Martel-Pelletier, J.; Pelletier, J.P. The role of cytokines in osteoarthritis pathophysiology. Biorheology 2002, 39, 237-246.

9. Lee, A.S.; Ellman, M.B.; Yan, D.; Kroin, J.S.; Cole, B.J.; van Wijnen, A.J.; Im, H.-J. A current review of molecular mechanisms regarding osteoarthritis and pain. Gene 2013, 527, 440-447, https://doi.org/10.1016/j.gene.2013.05.069.

10. Stannus, O.; Jones, G.; Cicuttini, F.; Parameswaran, V.; Quinn, S.; Burgess, J.; Ding, C. Circulating levels of IL- 6 and TNF- $\alpha$ are associated with knee radiographic osteoarthritis and knee cartilage loss in older adults. Osteoarthritis and cartilage 2010, 18, 1441-1447, https://doi.org/10.1016/j.joca.2010.08.016.

11. Weiss, E. Knee osteoarthritis, body mass index and pain: data from the Osteoarthritis Initiative. Rheumatology 2014, 53, 2095-2099, https://doi.org/10.1093/rheumatology/keu244.

12. Holla, J.F.; van der Leeden, M.; Knol, D.L.; Roorda, L.D.; van der Esch, M.; Voorneman, R.E.; Lems, W.F.; Dekker, J. The association of body-mass index and depressed mood with knee pain and activity limitations in knee osteoarthritis: results from the Amsterdam osteoarthritis cohort. BMC musculoskeletal disorders 2013, 14, https://doi.org/10.1186/1471-2474-14-296.

13. Iannone, F.; Lapadula, G. Obesity and inflammation-targets for OA therapy. Current drug targets 2010, 11, 586-598, https://doi.org/10.2174/138945010791011857.

14. Yusuf, E. Pharmacologic and non-pharmacologic treatment of osteoarthritis. Current Treatment Options in Rheumatology 2016, 2, 111-125, https://doi.org/10.1007/s40674-016-0042-y.

15. Banerjee, S.K.; Maulik, S.K. Effect of garlic on cardiovascular disorders: a review. Nutrition journal 2002 , 1, https://doi.org/10.1186/1475-2891-1-4.

16. Mahdizadeh, S.; Ghadiri, M.K.; Gorji, A. 'Avicenna's Canon of Medicine: a review of analgesics and antiinflammatory substances. Avicenna journal of phytomedicine 2015, 5.

17. Majewski, M. Allium sativum: facts and myths regarding human health. Roczniki Państwowego Zakładu Higieny 2014, 65.

18. Arreola, R.; Quintero-Fabián, S.; López-Roa, R.I.; Flores-Gutiérrez, E.O.; Reyes-Grajeda, J.P.; CarreraQuintanar, L.; Ortuño-Sahagún, D. Immunomodulation and anti-inflammatory effects of garlic compounds. Journal of immunology research 2015, 2015, https://doi.org/10.1155/2015/401630.

19. Lee, H.-S.; Lee, C.-H.; Tsai, H.-C.; Salter, D. Inhibition of cyclooxygenase 2 expression by diallyl sulfide on joint inflammation induced by urate crystal and IL-1 $\beta$. Osteoarthritis and Cartilage 2009, 17, 91-99, https://doi.org/10.1016/j.joca.2008.05.010.

20. Wollheim, F.A. Current Pharmacological Treatment of Osteoarthritis. Drugs 1996, 52, 27-38, https://doi.org/10.2165/00003495-199600523-00006.

21. Badr, G.M.; AL-Mulhim, J.A. The protective effect of aged garlic extract on non-steroidal anti-inflammatory drug-induced gastric inflammations in male albino rats. Evidence-Based Complementary and Alternative Medicine 2014, 2014, https://doi.org/10.1155/2014/759642.

22. Hosseinzadeh-Attar, M.J.; Alipoor, E.; Dehghani, S.; Salimzadeh, A. Increased efficacy of a garlic supplement on knee osteoarthritis symptoms in patients with obesity. Journal of Herbal Medicine 2020, 24, https://doi.org/10.1016/j.hermed.2020.100392.

23. Dehghani, S.; Alipoor, E.; Salimzadeh, A.; Yaseri, M.; Hosseini, M.; Feinle-Bisset, C.; Hosseinzadeh-Attar, M.J. The effect of a garlic supplement on the pro-inflammatory adipocytokines, resistin and tumor necrosis factor-alpha, and on pain severity, in overweight or obese women with knee osteoarthritis. Phytomedicine 2018, 48, 70-75, https://doi.org/10.1016/j.phymed.2018.04.060.

24. Salimzadeh, A.; Alipoor, E.; Dehghani, S.; Yaseri, M.; Hosseini, M.; Feinle-Bisset, C.; Hosseinzadeh-Attar, M.J. The effect of 12-week garlic supplementation on symptom relief in overweight or obese women with knee osteoarthritis. International journal of clinical practice 2018, 72.

25. Hussein, N.A.; Sharara, G.M. Poster 129: Effect of Garlic Versus Glucosamine Sulphate on Cartilage Degeneration and Clinical Manifestations in Patients with Knee Osteoarthritis. PM\&R 2009, 1, S160-S160.

26. Hussein, N.A.; Sharara, G.M. Poster 9: Effect of Combined Garlic Therapy and Comprehensive Rehabilitation Program Versus Comprehensive Rehabilitation Program Alone on Control of Clinical Manifestations and Quality of Life of Knee Osteoarthritis Patients. Archives of Physical Medicine and Rehabilitation 2007, 88, https://doi.org/10.1016/j.apmr.2007.06.584.

27. Lawson, L.D.; Hunsaker, S.M. Allicin bioavailability and bioequivalence from garlic supplements and garlic foods. Nutrients 2018, 10, https://doi.org/10.3390/nu10070812.

28. Adaki, S.; Adaki, R.; Shah, K.; Karagir, A. Garlic: Review of literature. Indian journal of cancer 2014, 51, https://doi.org/10.4103/0019-509X.175383.

29. Kim, C.; Linsenmeyer, K.D.; Vlad, S.C.; Guermazi, A.; Clancy, M.M.; Niu, J.; Felson, D.T. Prevalence of radiographic and symptomatic hip osteoarthritis in an urban United States community: the Framingham osteoarthritis study. Arthritis \& rheumatology 2014, 66, 3013-3017.

30. Khotib, J.; Setiawan, H.U.; Nurhan, A.D.; Rahadiansyah, E.; Ardianto, C.; Rahmadi, M. Analysis of effectiveness and drug related problems of pain reliever for knee osteoarthritis: weighing clinical risk and benefit. Journal of Basic and Clinical Physiology and Pharmacology 2020, 30, https://doi.org/10.1515/jbcpp-2019-0338. 
31. Mozaffari-Khosravi, H.; Hesabgar, H.-A.-S.; Owlia, M.-B.; Hadinedoushan, H.; Barzegar, K.; Fllahzadeh, M.H. The effect of garlic tablet on pro-inflammatory cytokines in postmenopausal osteoporotic women: a randomized controlled clinical trial. Journal of dietary supplements 2012, 9, 262-271, https://doi.org/10.3109/19390211.2012.726703.

32. Bliddal, H.; Leeds, A.; Christensen, R. Osteoarthritis, obesity and weight loss: evidence, hypotheses and horizons-a scoping review. Obesity reviews 2014, 15, 578-586, https://doi.org/10.1111/obr.12173.

33. Herikurniawan, H.; Isbagio, H.; Soewondo, P.; Diana, N.; Setiati, S. The Correlation between Body Fat Distribution and Medial Tibiofemoral Joint Space Width in Obese Knee Osteoarthritis Patients. Indonesian Journal of Rheumatology 2017, 9.

34. Conde, J.; Scotece, M.; Gomez, R.; Lopez, V.; Gomez-Reino, J.J.; Gualillo, O. Adipokines and osteoarthritis: novel molecules involved in the pathogenesis and progression of disease. Arthritis 2011, 2011, https://doi.org/10.1155/2011/203901.

35. King, L.K.; March, L.; Anandacoomarasamy, A. Obesity \& osteoarthritis. The Indian journal of medical research 2013, 138.

36. Darooghegi Mofrad, M.; Rahmani, J.; Kord Varkaneh, H.; Teymouri, A.; Mousavi, S.M. The effects of garlic supplementation on weight loss: A systematic review and meta-analysis of randomized controlled trials. International Journal for Vitamin and Nutrition Research 2018, https://doi.org/10.1024/03009831/a000607.

37. Hosseini, A.; Hosseinzadeh, H. A review on the effects of Allium sativum (Garlic) in metabolic syndrome. Journal of Endocrinological Investigation 2015, 38, 1147-1157, https://doi.org/10.1007/s40618-015-03138 .

38. Kim, Y.; Lee, M.-S.; Kim, J.-S.; Lee, H.-S. Garlic decreases body weight via decrease of serum lipid and increase of uncoupling proteins mRNA expression. The FASEB Journal 2007, 21, LB59-LB59.

39. Lee, M.-S.; Kim, I.-H.; Kim, C.-T.; Kim, Y. Reduction of body weight by dietary garlic is associated with an increase in uncoupling protein mRNA expression and activation of AMP-activated protein kinase in dietinduced obese mice. The Journal of nutrition 2011, 141, 1947-1953, https://doi.org/10.3945/jn.111.146050.

40. Keophiphath, M.; Priem, F.; Jacquemond-Collet, I.; Clément, K.; Lacasa, D. 1, 2-vinyldithiin from garlic inhibits differentiation and inflammation of human preadipocytes. The Journal of nutrition 2009, 139, 20552060, https://doi.org/10.3945/jn.109.105452.

41. Woodell-May, J.E.; Sommerfeld, S.D. Role of Inflammation and the Immune System in the Progression of Osteoarthritis. Journal of Orthopaedic Research® 2020, 38, 253-257, https://doi.org/10.1002/jor.24457.

42. Shen, J.; Abu-Amer, Y.; 'O'Keefe, R.J.; McAlinden, A. Inflammation and epigenetic regulation in osteoarthritis. Connective tissue research 2017, 58, 49-63, https://doi.org/10.1080/03008207.2016.1208655.

43. Griffin, T.M.; Scanzello, C.R. Innate inflammation and synovial macrophages in osteoarthritis pathophysiology. Clinical and experimental rheumatology 2019, 37 Suppl 120, 57-63.

44. Ansari, M.Y.; Ahmad, N.; Haqqi, T.M. Oxidative stress and inflammation in osteoarthritis pathogenesis: Role of polyphenols. Biomedicine \& Pharmacotherapy 2020, 129, https://doi.org/10.1016/j.biopha.2020.110452.

45. Chen, W.C.; Lu, Y.C.; Kuo, S.J.; Lin, C.Y.; Tsai, C.H.; Liu, S.C.; Chen, Y.L.; Wang, S.W.; Tang, C.H. Resistin enhances IL-1 $\beta$ and TNF- $\alpha$ expression in human osteoarthritis synovial fibroblasts by inhibiting miR-149 expression via the MEK and ERK pathways. FASEB journal : official publication of the Federation of American Societies for Experimental Biology 2020, 34, 13671-13684, https://doi.org/10.1096/fj.202001071R.

46. Moosavian, S.P.; Arab, A.; Paknahad, Z.; Moradi, S. The effects of garlic supplementation on oxidative stress markers: A systematic review and meta-analysis of randomized controlled trials. Complementary Therapies in Medicine 2020, 50, https://doi.org/10.1016/j.ctim.2020.102385

47. Yang, G.; Sun, S.; Wang, J.; Li, W.; Wang, X.; Yuan, L.; Li, S. S-Allylmercaptocysteine Targets Nrf2 in Osteoarthritis Treatment Through NOX4/NF-кB Pathway. Drug Design, Development and Therapy 2020, 14, 4533-4546, https://doi.org/10.2147/DDDT.S258973.

48. Cheng, H.; Huang, G.; Huang, H. The antioxidant activities of garlic polysaccharide and its derivatives. International Journal of Biological Macromolecules 2020, 145, 819-826, https://doi.org/10.1016/j.ijbiomac.2019.09.232

49. Malemud, C.J. Cytokines as therapeutic targets for osteoarthritis. BioDrugs 2004, 18, 23-35, https://doi.org/10.2165/00063030-200418010-00003.

50. Ho, C.Y.; Weng, C.J.; Jhang, J.J.; Cheng, Y.T.; Huang, S.M.; Yen, G.C. Diallyl sulfide as a potential dietary agent to reduce TNF- $\alpha$-and histamine-induced pro-inflammatory responses in A 7r5 cells. Molecular nutrition \& food research 2014, 58, 1069-1078, https://doi.org/10.1002/mnfr.201300617.

51. You, S.; Nakanishi, E.; Kuwata, H.; Chen, J.; Nakasone, Y.; He, X.; He, J.; Liu, X.; Zhang, S.; Zhang, B. Inhibitory effects and molecular mechanisms of garlic organosulfur compounds on the production of inflammatory mediators. Molecular nutrition \& food research 2013, 57, 2049-2060, https://doi.org/10.1002/mnfr.201200843. 
52. Kim, S.R.; Jung, Y.R.; An, H.J.; Kim, D.H.; Jang, E.J.; Choi, Y.J.; Moon, K.M.; Park, M.H.; Park, C.H.; Chung, K.W. Anti-wrinkle and anti-inflammatory effects of active garlic components and the inhibition of MMPs via NF-кB signaling. PloS one 2013, 8, https://doi.org/10.1371/journal.pone.0073877.

53. Arreola, R.; Quintero-Fabián, S.; López-Roa, R.I.; Flores-Gutiérrez, E O.; Reyes-Grajeda, J.P.; CarreraQuintanar, L.; Ortuño-Sahagún, D. Immunomodulation and Anti-Inflammatory Effects of Garlic Compounds. Journal of Immunology Research 2015, 2015, https://doi.org/10.1155/2015/401630.

54. Mirzavandi, F.; Mollahosseini, M.; Salehi-Abargouei, A.; makiabadi, E.; Mozaffari-Khosravi, H. Effects of garlic supplementation on serum inflammatory markers: A systematic review and meta-analysis of randomized controlled trials. Diabetes \& Metabolic Syndrome: Clinical Research \& Reviews 2020, 14, 1153-1161, https://doi.org/10.1016/j.dsx.2020.06.031.

55. Darooghegi M.M.; Milajerdi, A.; Koohdani, F.; Surkan, P.J.; Azadbakht, L. Garlic Supplementation Reduces Circulating C-reactive Protein, Tumor Necrosis Factor, and Interleukin-6 in Adults: A Systematic Review and Meta-analysis of Randomized Controlled Trials. The Journal of Nutrition 2019, 149, 605-618, https://doi.org/10.1093/jn/nxy310.

56. Steppan, C.M.; Bailey, S.T.; Bhat, S.; Brown, E.J.; Banerjee, R.R.; Wright, C.M.; Patel, H.R.; Ahima, R.S.; Lazar, M.A. The hormone resistin links obesity to diabetes. Nature 2001, 409, 307-312, https://doi.org/10.1038/35053000.

57. Lee, J.; Ort, T.; Ma, K.; Picha, K.; Carton, J.; Marsters, P.; Lohmander, L.; Baribaud, F.; Song, X.-Y.; Blake, $\mathrm{S}$. Resistin is elevated following traumatic joint injury and causes matrix degradation and release of inflammatory cytokines from articular cartilage in vitro. Osteoarthritis and Cartilage 2009, 17, 613-620, https://doi.org/10.1016/j.joca.2008.08.007.

58. Bokarewa, M.; Nagaev, I.; Dahlberg, L.; Smith, U.; Tarkowski, A. Resistin, an adipokine with potent proinflammatory properties. The Journal of Immunology 2005, 174, 5789-5795, https://doi.org/10.4049/jimmunol.174.9.5789.

59. Zhang, Z.; Xing, X.; Hensley, G.; Chang, L.W.; Liao, W.; Abu-Amer, Y.; Sandell, L.J. Resistin induces expression of pro-inflammatory cytokines and chemokines in human articular chondrocytes via transcription and messenger RNA stabilization. Arthritis \& Rheumatism 2010, 62, 1993-2003, https://dx.doi.org/10.1002\%2Fart.27473.

60. De Boer, T.; Van Spil, W.; Huisman, A.; Polak, A.; Bijlsma, J.; Lafeber, F.; Mastbergen, S. Serum adipokines in osteoarthritis; comparison with controls and relationship with local parameters of synovial inflammation and cartilage damage. Osteoarthritis and cartilage 2012, 20, 846-853, https://doi.org/10.1016/j.joca.2012.05.002.

61. Schwartz, D.R.; Lazar, M.A. Human resistin: found in translation from mouse to man. Trends in Endocrinology \& Metabolism 2011, 22, 259-265, https://doi.org/10.1016/j.tem.2011.03.005.

62. Koskinen, A.; Vuolteenaho, K.; Moilanen, T.; Moilanen, E. Resistin as a factor in osteoarthritis: synovial fluid resistin concentrations correlate positively with interleukin 6 and matrix metalloproteinases MMP-1 and MMP-3. Scandinavian Journal of Rheumatology 2014, 43, 249-253, https://doi.org/10.3109/03009742.2013.853096.

63. Huang, J.; Liu, L.; Yang, J.; Ding, J.; Xu, X. IncRNA DILC is downregulated in osteoarthritis and regulates IL-6 expression in chondrocytes. Journal of cellular biochemistry 2019, 120, 16019-16024, https://doi.org/10.1002/jcb.28880.

64. Doss, F.; Menard, J.; Hauschild, M.; Kreutzer, H.J.; Mittlmeier, T.; Müller-Steinhardt, M.; Müller, B. Elevated IL-6 levels in the synovial fluid of osteoarthritis patients stem from plasma cells. Scandinavian journal of rheumatology 2007, 36, 136-139, https://doi.org/10.1080/03009740701250785.

65. Quintero-Fabián, S.; Ortuño-Sahagún, D.; Vázquez-Carrera, M.; López-Roa, R.I. Alliin, a garlic (Allium sativum) compound, prevents LPS-induced inflammation in 3T3-L1 adipocytes. Mediators of inflammation 2013, 2013, https://doi.org/10.1155/2013/381815.

66. Vincent, T.L. IL-1 in osteoarthritis: time for a critical review of the literature. F1000Research 2019, 8, https://doi.org/10.12688/f1000research.18831.1.

67. Liao, C.-R.; Wang, S.-N.; Zhu, S.-Y.; Wang, Y.-Q.; Li, Z.-Z.; Liu, Z.-Y.; Jiang, W.-S.; Chen, J.-T.; Wu, Q. Advanced oxidation protein products increase TNF- $\alpha$ and IL- $1 \beta$ expression in chondrocytes via NADPH oxidase 4 and accelerate cartilage degeneration in osteoarthritis progression. Redox biology 2020, 28, https://doi.org/10.1016/j.redox.2019.101306.

68. Roy, H.S.; Dubey, G.; Sharma, V.K.; Bharatam, P.V.; Ghosh, D. Molecular docking and molecular dynamics to identify collagenase inhibitors as lead compounds to address osteoarthritis. Journal of Biomolecular Structure and Dynamics 2020, 1-13, https://doi.org/10.1080/07391102.2020.1838326.

69. Nissinen, L.; Kähäri, V.-M. Matrix metalloproteinases in inflammation. Biochimica et Biophysica Acta (BBA)-General Subjects 2014, 1840, 2571-2580, https://doi.org/10.1016/j.bbagen.2014.03.007.

70. Paiva, K.B.; Granjeiro, J.M. Matrix metalloproteinases in bone resorption, remodeling, and repair. In: Progress in molecular biology and translational science. Elsevier, Volume 148, 2017; pp 203-303, https://doi.org/10.1016/bs.pmbts.2017.05.001. 
71. Jackson, M.T.; Moradi, B.; Smith, M.M.; Jackson, C.J.; Little, C.B. Activation of matrix metalloproteinases 2,9 , and 13 by activated protein $\mathrm{C}$ in human osteoarthritic cartilage chondrocytes. Arthritis \& rheumatology 2014, 66, 1525-1536, https://doi.org/10.1002/art.38401.

72. Ko, J.H.; Kang, Y.M.; Yang, J.H.; Kim, J.S.; Lee, W.J.; Kim, S.H.; Yang, I.H.; Moon, S.H. Regulation of MMP and TIMP expression in synovial fibroblasts from knee osteoarthritis with flexion contracture using adenovirus-mediated relaxin gene therapy. The Knee 2019, 26, 317-329, https://doi.org/10.1016/j.knee.2019.01.010.

73. Kim, M.-J.; Kang, B.-H.; Park, S.-H.; Kim, B.; Lee, G.-Y.; Seo, Y.-M.; Park, K.-S.; Yoo, J.-I. Association of the Western Ontario and McMaster Universities Osteoarthritis Index (WOMAC) with Muscle Strength in Community-Dwelling Elderly with Knee Osteoarthritis. International Journal of Environmental Research and Public Health 2020, 17, https://doi.org/10.3390/ijerph17072260.

74. Bellamy, N.; Buchanan, W.W.; Goldsmith, C.H.; Campbell, J.; Stitt, L.W. Validation study of WOMAC: a health status instrument for measuring clinically important patient relevant outcomes to antirheumatic drug therapy in patients with osteoarthritis of the hip or knee. Journal of rheumatology 1988, 15, 1833-40.

75. Dieppe, P.A.; Lohmander, L.S. Pathogenesis and management of pain in osteoarthritis. The Lancet 2005, 365, 965-973, https://doi.org/10.1016/S0140-6736(05)71086-2.

76. Vincent, T.L. Peripheral pain mechanisms in osteoarthritis. Pain 2020, 161, https://dx.doi.org/10.1097\%2Fj.pain.0000000000001923.

77. Jacobs, C.A.; Vranceanu, A.-M.; Thompson, K.L.; Lattermann, C. Rapid progression of knee pain and osteoarthritis biomarkers greatest for patients with combined obesity and depression: data from the osteoarthritis initiative. Cartilage 2020, 11, 38-46, https://doi.org/10.1177/1947603518777577.

78. Boer, C.G.; Radjabzadeh, D.; Medina-Gomez, C.; Garmaeva, S.; Schiphof, D.; Arp, P.; Koet, T.; Kurilshikov, A.; Fu, J.; Ikram, M.A. Intestinal microbiome composition and its relation to joint pain and inflammation. Nature communications 2019, 10, 1-9, https://doi.org/10.1038/s41467-019-12873-4.

79. Valdes, A.M. Metabolic syndrome and osteoarthritis pain: common molecular mechanisms and potential therapeutic implications. Osteoarthritis Cartilage 2020, 28, 7-9, https://doi.org/10.1016/j.joca.2019.06.015.

80. Fisher, N.M.; Gresham, G.E.; Abrams, M.; Hicks, J.; Horrigan, D.; Pendergast, D.R. Quantitative effects of physical therapy on muscular and functional performance in subjects with osteoarthritis of the knees. Archives of physical medicine and rehabilitation 1993, 74, 840-847, https://doi.org/10.1016/00039993(93)90011-x.

81. Minor, M.A. Exercise in the management of osteoarthritis of the knee and hip. Arthritis \& Rheumatism: Official Journal of the American College of Rheumatology 1994, 7, 198-204, https://doi.org/10.1097/bor.0000000000000478.

82. Ettinger, W.H.; Afable, R.F. Physical disability from knee osteoarthritis: the role of exercise as an intervention. Medicine \& Science in Sports \& Exercise 1994, 26, 1435-40.

83. Kim, I.J.; Kim, H.A.; Seo, Y.-I.; Jung, Y.O.; Song, Y.W.; Jeong, J.Y.; Kim, D.H. Prevalence of knee pain and its influence on quality of life and physical function in the Korean elderly population: a community based cross-sectional study. Journal of Korean medical science 2011, 26, 1140-1146, https://doi.org/10.3346/jkms.2011.26.9.1140.

84. Creamer, P.; Lethbridge-Cejku, M.; Hochberg, M. Factors associated with functional impairment in symptomatic knee osteoarthritis. Rheumatology 2000, 39, 490-496, https://doi.org/10.1093/rheumatology/39.5.490.

85. Davis, M.; Ettinger, W.; Neuhaus, J.; Mallon, K. Knee osteoarthritis and physical functioning: evidence from the NHANES I Epidemiologic Followup Study. The Journal of rheumatology 1991, 18.

86. Perrot, S.; Poiraudeau, S.; Kabir-Ahmadi, M.; Rannou, F. Correlates of pain intensity in men and women with hip and knee osteoarthritis. Results of a national survey: The French ARTHRIX study. The Clinical journal of pain 2009, 25, 767-772, https://doi.org/10.1097/ajp.0b013e3181b43d4f.

87. Kaukinen, P.; Podlipská, J.; Guermazi, A.; Niinimäki, J.; Lehenkari, P.; Roemer, F.; Nieminen, M.; Koski, J.; Saarakkala, S.; Arokoski, J. Magnetic resonance imaging (MRI)-defined cartilage degeneration and joint pain are associated with poor physical function in knee osteoarthritis-the Oulu Knee Osteoarthritis study. Osteoarthritis and Cartilage 2017, 25, 1829-1840, https://doi.org/10.1016/j.joca.2017.07.002.

88. Fitzsimmons, S.E.; Vazquez, E.A.; Bronson, M.J. How to Treat the Stiff Total Knee Arthroplasty?: A Systematic Review. Clinical Orthopaedics and Related Research $\AA$ 2010, 468, 1096-1106, https://doi.org/10.1007/s11999-010-1230-y. 


\section{Supplementary Materials}

Table S1. Modified jadad score of reviewed studies

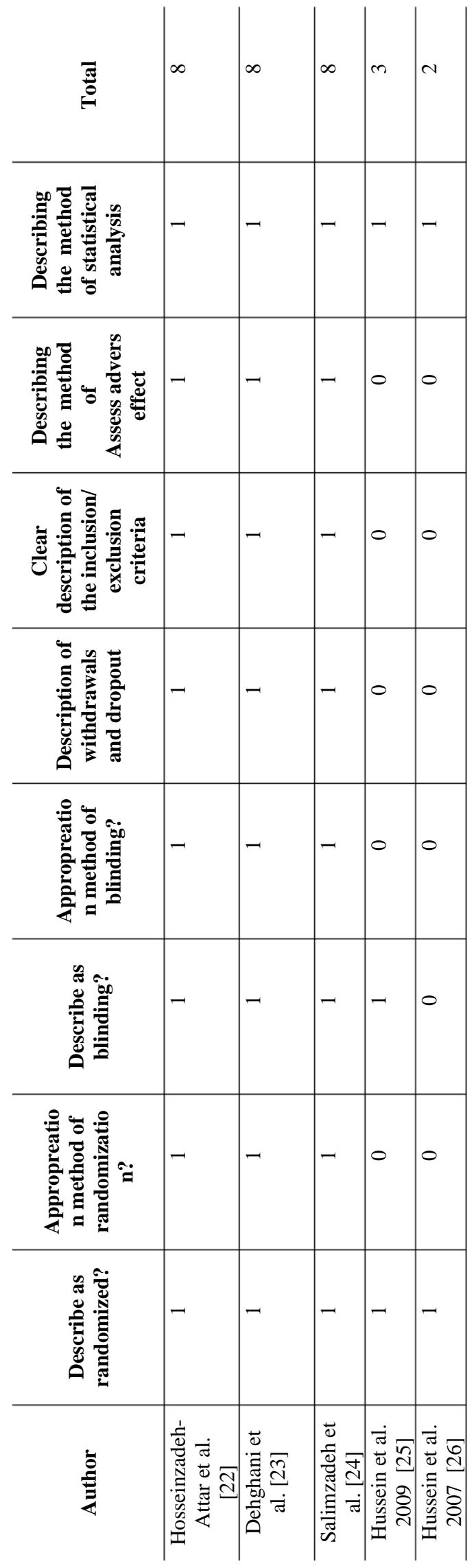

